\title{
Local Stability Theory for Caputo Fractional Planar System and Application to Predator-Prey Model with Group Defense
}

\author{
Marvin $\operatorname{Hoti}^{1}$ \\ ${ }^{1}$ Ryerson University
}

July 17, 2020

\begin{abstract}
In this manuscript we show a new approach into analyzing the local stability of equilibrium points of non-linear Caputo fractional planar systems. It is shown that the equilibrium points of such systems can exhibit an unstable focus or stable focus under suitable conditions. Further, it is shown that for $\$ \backslash$ alpha $\$$ close to $\$ 1, \$$ global stability can be concluded, under suitable conditions, and without the use of a Lyapunov function. Lastly, our results are applied to a predator prey model with group defense, in which we show that it had equilibrium points that undergo an unstable focus and a stable focus.
\end{abstract}

\section{Hosted file}

July122020.pdf available at https://authorea.com/users/343854/articles/470438-localstability-theory-for-caputo-fractional-planar-system-and-application-to-predator-preymodel-with-group-defense 